\title{
Los crímenes de genocidio, lesa humanidad y de guerra. Notas para su incorporación a la legislación mexicana
}

\section{Crime of Genocide, Crimes Against Humanity and War Crimes. Notes for Incorporation Into Mexican Law}

\section{Arturo Villarreal Palos*}

SUMARIO: I. Introducción. II. Obligaciones contenidas en el Estatuto de Roma de la Corte Penal Internacional. III. Tentativas de incorporación de los tipos penales del derecho internacional penal en la legislación nacional. IV. El delito de genocidio. V. Los crímenes de lesa humanidad. VI. Los crímenes de guerra. VII. Conclusiones.

* Doctor en Derecho por la UNAM; especialista en Derecho Penal. Profesor-investigador en el Departamento de Derecho Público del Centro Universitario de Ciencias Sociales y Humanidades de la Universidad de Guadalajara. Miembro del Sistema Nacional de Investigadores, Nivel II, Conacyt, México. 
Resumen: De la firma del Estatuto de Roma de la Corte Penal Internacional por parte de México, derivan compromisos implícitos y explícitos que es necesario cumplir. De una parte, la obligación de tipificar, en el ámbito interno, los delitos competencia de la Corte y, de la otra, la obligación explícita de contar con disposiciones internas que permitan sancionar los delitos cometidos contra la administración de justicia en procedimientos efectuados en la Corte o en conexión con ella y que también permitan asegurar los procedimientos aplicables a todas las formas de cooperación previstas en el Estatuto. El presente trabajo explora las diversas formas en que los Estados han procurado cumplir con estas obligaciones y propone las vías que serían más factibles en el caso de México, haciendo especial referencia los crímenes de genocidio, lesa humanidad y de guerra.

Palabras clave: incorporación, crímenes de genocidio, lesa humanidad y de guerra, México

ABSTRACT: Mexico's signature of the Rome Statute of the International Criminal Court, derive implicit and explicit commitments that must be met. On the one hand, the obligation to define, in the domestic sphere, crimes jurisdiction of the Court and, on the other, the obligation to have in place provisions penalizing offenses against the administration of justice in procedures performed at court or in connection with it and also allow secure procedures applicable to all forms of cooperation envisaged in the Statute. This paper explores the various ways in which States have sought to fulfill these obligations and proposes ways that would be more feasible in the case of Mexico, with particular reference to the crime of genocide, crimes against humanity and war crimes.

Key words: incorporation, crime of genocide, crimes against humanity and war crimes, Mexico.

RÉSUMÉ: De la signature du Mexique du Statut de Rome de la Cour pénale internationale, tirent des engagements implicites et explicites qui doivent être respectées. D'une part, l'obligation de définir, dans la sphère domestique, les crimes compétence de la Cour et l'autre, l'obligation explicite d'avoir des dispositions internes qui pénalisent les infractions contre l'administration de la justice dans les procédures effectuées à la cour ou en relation avec elle et aussi permettre l'existence de procédures applicables à toutes les formes de coopération prévues dans le Statut. Cet article explore les différentes façons dont les États ont cherché à répondre à ces obligations et propose des moyens qui seraient plus possible dans le cas du Mexique, avec une référence particulière aux crimes de génocide, crimes contre l'humanité et crimes de guerre.

Mots-clés: incorporation, crimes de génocide, crimes contre l'humanité et crimes de guerre, Mexique. 


\section{INTRODUCCIÓN}

De la firma del Estatuto de Roma de la Corte Penal Internacional (ER o Estatuto) por parte de México, ${ }^{1}$ derivan obligaciones frente a la comunidad internacional que es necesario cumplir. En el presente trabajo me refiero a esas obligaciones y a la forma en que podríamos satisfacerlas de mejor manera.

A esos efectos, analizo, en primer término, algunas de las experiencias internacionales en materia de implementación del Estatuto, para luego pasar a realizar una revisión de las tentativas de incorporación de los tipos penales del derecho internacional penal en la legislación nacional, finalizando con una propuesta sobre cómo incorporar en nuestra ley penal el delito de genocidio, los crímenes de lesa humanidad y los crímenes de guerra.

Utilizo para ello una metodología basada en la comparación jurídica entre normas internacionales y nacionales, la remisión a normas de nuestro propio sistema jurídico, el análisis legal y de la doctrina existente, así como la síntesis, lo que da como resultado la propuesta que arriba he enunciado. Si bien éste no es un tema urgente en la agenda legislativa, indudablemente constituye un compromiso internacional que México debe cumplir. De ahí la relevancia de la temática abordada.

\section{OBligaCiOnES CONTENIDAS EN El Estatuto DE ROMA DE LA CORTE PENAL INTERNACIONAL}

Respecto a qué tipo de obligaciones se desprenden de la firma del ER, hay coincidencia en que existen obligaciones que están implícitas y hay otras que se prevén explícitamente.

En cuanto a la primera de estas obligaciones, existe consenso en que del Estatuto no deriva una expresa obligación para tipificar, en el ámbito interno, los delitos que son competencia de la Corte Penal Internacional

1 México firmó el Estatuto de Roma el 7 de septiembre de 2000 y lo ratificó el 28 de octubre de 2005, luego de agotar el proceso de reforma constitucional que se consideró necesario para ese objeto. 
Esta revista forma parte del acervo de la Biblioteca Jurídica Virtual del Instituto de Investigaciones Jurídicas de la UNAM

(CPI o la Corte). Sin embargo, esta obligación se estima implícita desde el momento en que la Corte, al tenor de los artículos 1o. y 17 del Estatuto, se considera complementaria de las jurisdicciones penales nacionales, siendo éstas a quienes compete juzgar, en primera instancia, los crímenes más graves de trascendencia internacional. ${ }^{2}$

Además, de manera expresa, en el Preámbulo del Estatuto se señala que los crímenes más graves de trascendencia para la comunidad internacional no deben quedar sin castigo y que para tal fin, hay que adoptar medidas en el plano nacional, además de que es deber de todo Estado ejercer su jurisdicción penal contra los responsables de crímenes internacionales.

Ahora bien, frente a esta obligación implícita, existen dos explícitas:

a) La señalada en el artículo 70.4. a del Estatuto, según la cual todo Estado parte hará extensivas sus leyes penales que castiguen los delitos contra la integridad de su propio procedimiento de investigación o enjuiciamiento a los delitos contra la administración de justicia a que se hace referencia en el artículo 70.1 y sean cometidos en su territorio o por uno de sus nacionales, ${ }^{3} \mathrm{y}$

b) El artículo 88 del Estatuto señala que los Estados parte se asegurarán de que en el derecho interno existan procedimientos aplicables a todas las formas de cooperación especificadas en su parte IX, como lo son, entre otras, la entrega de personas a la Corte, la detención provisional y otras formas de cooperación, tales como identificar y buscar personas u objetos, practicar pruebas, dictámenes e informes periciales o interrogar a una persona.

2 Al respecto, véase, Ambos, Kai, "Implementación del Estatuto de Roma en la legislación nacional”, en Ambos, Kai y Malarino, Ezequiel (eds.), Persecución penal nacional de crímenes internacionales en América Latina y España, Uruguay, Fundación Konrad-Adenauer-Stiftung, 2003, p. 25; Dondé Matute, Francisco Javier, “Consideraciones en torno a la implementación de los crímenes que son competencia de la Corte Penal Internacional”, Anuario Mexicano de Derecho Internacional, México, vol. VII, 2007 p. 117.

3 El artículo 70.1 del ER establece los delitos contra la administración de justicia que pueden cometerse en los procedimientos seguidos en la Corte. A saber: dar falso testimonio, presentar pruebas falsas, corromper a un testigo, obstruir su comparecencia, tomar represalias contra el, destruir o alterar pruebas o interferir en las diligencias de prueba, poner trabas, intimidar, corromper o tomar represalias contra un funcionario de la Corte y solicitar o aceptar un soborno. 
Esta revista forma parte del acervo de la Biblioteca Jurídica Virtual del Instituto de Investigaciones Jurídicas de la UNAM

Sobre cómo cumplir con estas obligaciones, las naciones han ensayado fundamentalmente dos vías: a) la de expedir leyes especiales, que pueden o no incluir las tres obligaciones antes enunciadas y $b$ ) la de realizar reformas en su codificación penal para incluir los delitos competencia de la Corte, a la par de expedir leyes especiales en materia de cooperación.

Tocante a Latinoamérica, Argentina ${ }^{4}$ y Uruguay ${ }^{5}$ han expedido leyes especiales que contemplan los tres aspectos: los tipos penales del derecho internacional penal (genocidio, crímenes de lesa humanidad y crímenes de guerra), los delitos contra la administración de justicia y las formas de cooperación. Argentina regula los tipos penales del derecho internacional en un modelo que hace remisión directa al Estatuto, mientras que Uruguay los describe en su propia ley. Chile también ha expedido una ley especial, aunque en este caso limitada a la tipificación de los crímenes competencia de la Corte. ${ }^{6}$

Costa Rica modificó su Código Penal, a efecto de incorporar los crímenes de genocidio, lesa humanidad y de guerra. ${ }^{7}$ El Código Penal Colombiano contiene disposiciones para sancionar el genocidio, ciertos crímenes de lesa humanidad como la tortura y la desaparición forzada, así como un capítulo sobre "Delitos contra personas y bienes protegidos por el Derecho Internacional Humanitario” y, en su Código Procesal Penal, tiene una cláusula general hacia la CPI en la sección correspondiente a mecanismos de cooperación internacional, caso similar al de Perú, que en su legislación

4 Véase la Ley 26.200 de Implementación del Estatuto de Roma, publicada en el Boletín Oficial de la República Argentina el 9 de enero 5 de 2007, disponible en: http: / /www.iccnow. org/documents/Ley_de_implementacion_argentina2.pdf(fecha de consulta: 20 de abril de 2016).

5 Véase la Ley núm. 18.026 de Cooperación con la Corte Penal Internacional en Materia de Lucha contra el Genocidio, los Crímenes de Guerra y de Lesa Humanidad, publicada en el Diario Oficial de la República Oriental del Uruguay el 4 de octubre de 2006, disponible en: http: / / www2.ohchr.org/english/bodies/cat/docs/AnexoI_Ley18026.pdf (fecha de consulta: 20 de abril de 2016).

6 Véase la Ley núm. 20.357. Tipifica Crímenes de Lesa Humanidad y Genocidio y Crímenes y Delitos de Guerra, publicada en el Diario Oficial de la República de Chile el 18 de julio de 2009, disponible en: https: / / www.leychile.cl/ Navegar?idNorma=1004297 (fecha de consulta: 20 de abril de 2016).

7 Véase la Ley núm. 8272 del 2 de mayo de 2002 de Costa Rica. Represión Penal como Castigo por los Crímenes de Guerra y de Lesa Humanidad, disponible en: http: / /www.acnur. org/t3/fileadmin/Documentos/BDL/2002/1847.pdf?view=1 (fecha de consulta: 20 de abril de 2016). 
Esta revista forma parte del acervo de la Biblioteca Jurídica Virtual del Instituto de Investigaciones Jurídicas de la UNAM

procesal penal (libro VII, Sección VII), contempla los mecanismos de cooperación con la CPI. ${ }^{8}$

En el caso de Alemania han sido dictadas dos leyes especiales tanto de naturaleza material como también procesal: el Código Penal Internacional, que contiene los delitos de genocidio, contra la humanidad y de guerra, regulando además la responsabilidad de los jefes y otros superiores, y la Ley para la Implementación del Estatuto de Roma de la CPI, que a su vez contiene la Ley sobre la Cooperación con la CPI. ${ }^{9}$

Finalmente, España expresamente incorporó en su Código Penal los delitos de genocidio, de lesa humanidad, contra las personas y bienes protegidos en caso de conflicto armado y el de contra la administración de justicia de la Corte Penal Internacional, ${ }^{10}$ y adicionalmente, expidió la Ley Orgánica de Cooperación con la Corte Penal Internacional. ${ }^{11}$

Conforme a lo anterior, en los sucesivos apartados analizaremos cuál de estos modelos podría ser el más conveniente para nuestro país, haciendo la aclaración de que, en esta primera aproximación me voy a referir únicamente a los crímenes de genocidio, lesa humanidad y de guerra, quedando pendiente, para una segunda entrega, la cuestión relacionada con el crímen de agresión, los delitos contra la administración de justicia y la cooperación con la Corte Penal Internacional.

8 Sobre esto último, véase Herencia Carrasco, Salvador Martín, La implementación del Estatuto de Roma en la Región Andina. Los casos de Bolivia, Colombia y Perú, Perú, Comisión Andina de Juristas, 2015, pp. 24 y 26.

9 Sobre esta cuestión, véase Ambos, Kai, "La implementación del Estatuto de la Corte Penal Internacional en Alemania”, Revista Electrónica de Ciencia Penal y Criminología, España, núm. 7, 2005, pp. 4 y 18, disponible en: http: / / criminet.ugr.es/recpc/07/recpc07-17.pdf (fecha de consulta: 20 de abril de 2016), y también la Ley de Introducción del Código Penal Internacional (Alemania) del 26 de junio de 2002, disponible en: https: / /www.mpicc.de/files/pdf1 / vstgblspan1.pdf (fecha de consulta: 20 de abril de 2016).

10 Véase la Ley Orgánica 10/1995, del 23 de noviembre, del Código Penal Español, publicado en el Boletín Oficial del Estado núm. 281, del 24 de noviembre de 1995, artículos 471 bis, 607, 607 bis, 608 y subsiguientes, disponible en: https: / / www.boe.es/buscar/act.php?id=BOEA-1995-25444 (fecha de consulta: 23 de abril de 2016).

11 Véase la Ley Orgánica 18/2003, de 10 de diciembre, de Cooperación con la Corte Penal Internacional (España), publicada en el Boletín Oficial del Estado núm. 296 del 11 de diciembre de 2003, disponible en: https: / / www.boe.es/buscar/pdf/2003 / BOE-A-2003-22715-consolidado. pdf (fecha de consulta: 23 de abril de 2016). 
Esta revista forma parte del acervo de la Biblioteca Jurídica Virtual del Instituto de Investigaciones Jurídicas de la UNAM

\section{TENTATIVAS DE INCORPORACIÓN DE LOS TIPOS PENALES DEL DERECHO \\ INTERNACIONAL PENAL EN LA LEGISLACIÓN NACIONAL}

A la fecha hemos conocido de tres iniciativas de ley que buscan incorporar los delitos competencia de la CPI en el Código Penal Federal (CPF). La primera de ellas fue la que presentaron, en enero de 2008, las entonces diputadas del Partido Acción Nacional (PAN), Omeheira López Reyna y Esmeralda Cárdenas Sánchez, quienes elaboraron un proyecto de decreto para reformar y adicionar diversas disposiciones del Código Penal Federal, del Código de Justicia Militar, de la Ley General de Salud y del Código Federal de Procedimientos Penales. ${ }^{12}$

En términos generales, esta iniciativa planteó leves modificaciones al delito de genocidio, ya contemplado en el CPF, y la inclusión de un capítulo relativo a los "Delitos de lesa humanidad" y otro dedicado a "Delitos contra las personas y bienes protegidos por el derecho internacional humanitario".

La principal crítica que se puede hacer a este proyecto es su deficiente sistematicidad, ${ }^{13}$ pues, tocante a los delitos de lesa humanidad, si bien plantea una definición genérica que toma los elementos contextuales básicos de este delito acorde al ER - como lo son los actos cometidos como parte de un ataque generalizado o sistemático contra una población civil y con conocimiento de dicho ataque-, hace remisiones inadecuadas a diversos articulos del CPF que no se relacionan con los delitos de lesa humanidad reconocidos por el Estatuto; por ejemplo, los relacionados con la pornografía infantil, el abuso sexual, el estupro y el hostigamiento sexual y, en lo tocante a las remisiones a los delitos que sí se relacionan con el Estatuto, por ejemplo, homicidio, privación ilegal de la libertad, desaparición forzada y tortura, hay una falta de técnica, pues los reenvíos incluyen las penas para

12 Véase la Iniciativa con proyecto de decreto, que reforma y adiciona diversas disposiciones del Código Penal Federal, del Código de Justicia Militar, de la Ley General de Salud y del Código Federal de Procedimientos Penales, a cargo de la diputada Omeheira López Reyna, del Grupo Parlamentario del PAN, publicada en la Gaceta Parlamentaria de la Cámara de Diputados, año XI, núm. 2417-I, 4 de enero de 2008.

13 En este sentido, Guerrero Rosales, Humberto Francisco y Sirvent Bravo Ahuja, María (coords.), Manual para la Implementación del Estatuto de Roma en la Legislación Mexicana, México, Comisión Mexicana de Defensa y Promoción de los Derechos Humanos, 2008, p. 26. 
Esta revista forma parte del acervo de la Biblioteca Jurídica Virtual del Instituto de Investigaciones Jurídicas de la UNAM

cada delito, que se supone quedan ya comprendidas en la sanción genérica prevista para el delito de lesa humanidad. Asimismo, el genocidio, que tiene identidad propia es, a la vez, considerado como delito de lesa humanidad.

Respecto a los "Delitos contra las personas y bienes protegidos por el derecho internacional humanitario", igualmente se observa un problema con las remisiones a diversos tipos penales que no forman parte del derecho internacional humanitario; por ejemplo, las conductas relacionadas con el libre desarrollo de la personalidad de los menores, además de que, en términos de la redacción del artículo, no se está creando un delito o delitos, sino una agravante que aplica cuando el sujeto pasivo son personas y bienes protegidos por el derecho internacional humanitario.

La segunda de las iniciativas comentadas, es la que presentó, en febrero de 2012, el entonces diputado del Grupo Parlamentario del Partido del Trabajo (PT), Jaime Fernando Cárdenas Gracia, para reformar y adicionar diversas disposiciones del Código Penal Federal. ${ }^{14}$

Esta iniciativa hace una transcripción completa en el CPF de los crímenes de genocidio y de guerra contemplados en el ER y, tocante a los crímenes de lesa humanidad, hace un traslado casi idéntico, pero también incurre en el error de hacer remisiones a diversos tipos penales que no forman parte de los delitos de lesa humanidad contemplados en el ER, como son las conductas relacionadas con el libre desarrollo de la personalidad de los menores.

Finalmente, en mayo de 2015, las senadoras Gabriela Cuevas Barrón y María del Pilar Ortega Martínez, del Grupo Parlamentario del PAN, presentaron también una iniciativa con proyecto de decreto por el que se reforman y adicionan diversas disposiciones del Código Penal Federal en materia de delitos contra la humanidad. ${ }^{15}$

La propuesta de las senadoras del PAN fue en el sentido de trasladar integramente al CPF los delitos de genocidio, lesa humanidad y de guerra previstos en el ER.

14 Véase la Iniciativa que reforma y adiciona diversas disposiciones del Código Penal Federal, a cargo del diputado Jaime Fernando Cárdenas Gracia, del Grupo Parlamentario del PT, publicada en la Gaceta Parlamentaria de la Cámara de Diputados, año XV, núm. 3452-IV, 16 de febrero de 2012.

15 Véase la Iniciativa con proyecto de decreto por el que se reforman y adicionan diversas disposiciones del Código Penal Federal en materia de delitos contra la humanidad, a cargo de las Senadoras Gabriela Cuevas Barrón y María del Pilar Ortega Martínez, del Grupo Parlamentario del PAN, publicada en la Gaceta del Senado el 13 de mayo de 2015, Gaceta LXII/3SPR-3. 
Esta revista forma parte del acervo de la Biblioteca Jurídica Virtual del Instituto de Investigaciones Jurídicas de la UNAM

Sobre esto, ya se ha adelantado que algunos de los tipos penales contenidos en el ER, pueden ser contrarios al principio de legalidad, por la vía de la violación al principio de taxatividad, según el cual al legislador le es exigible la emisión de normas claras, precisas y exactas respecto de la conducta reprochable, así como de la consecuencia jurídica por la comisión de un ilícito. ${ }^{16}$

Al respecto, Alfredo Chirino ha señalado que los tipos penales o familias delictivas contempladas en el ER tienen serios problemas de descripción, no sólo por la existencia de fórmulas vagas que pretenden adelantarse a todos los posibles casos que se puedan producir en la realidad, sino también por los aspectos subjetivos que incluyen y que permiten una tarea muy amplia de interpretación para el juzgador. ${ }^{17}$

De manera específica, podemos aludir al artículo 7o., párrafo 1, letra K (relativo a los crímenes de lesa humanidad) del ER, que sanciona "otros actos inhumanos de carácter similar que causen intencionalmente grandes sufrimientos o atenten gravemente contra la integridad física o la salud mental o física”, cuya amplitud resulta opinable desde el punto de vista del principio de legalidad, ${ }^{18}$ lo que también ocurre con la referencia a los daños "claramente excesivos" en relación con la ventaja militar en los crímenes de guerra (artículo 8.2, b, iv, del ER). ${ }^{19}$

En ese tenor, no parece aconsejable un traslado automático a la legislación nacional de los tipos penales del Estatuto, sin un previo análisis a la luz

16 Sobre este particular, véase la tesis de jurisprudencia bajo el rubro: "PRINCIPIO DE LEGALIDAD PENAL EN SU VERTIENTE DE TAXATIVIDAD. ANÁLISIS DEL CONTEXTO EN EL CUAL SE

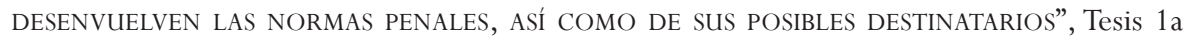
CXCII/2011 (9a), Semanario Judicial de la Federación y su Gaceta, Décima Época, octubre de 2011 , t. 2, p. 1094. Asimismo, y de acuerdo con Roxin, una de las consecuencias del principio de legalidad en materia penal es la prohibición de las leyes penales y penas indeterminadas. Véase Roxin, Claus, Derecho penal. Parte general. Fundamentos. La estructura de la teoría del delito, trad. y notas de Diego Manuel Luzón Peña, Miguel Díaz y García Conlledo y Javier de Vicente Remesal, España, Civitas, 2000, p. 141.

17 Véase Chirino Sánchez, Alfredo, "La reforma penal y los delitos competencia de la Corte Penal Internacional”, en Boeglin, Nicolás et al. (eds.), La Corte Penal Internacional: una perspectiva latinoamericana, Costa Rica, Universidad para la Paz de las Naciones Unidas-University Press, 2012, p. 71.

18 En este sentido, Cárdenas Aravena, Claudia, "La implementación de los crímenes competencia de la Corte Penal Internacional en la Ley No. 20.357”, Revista de Derecho, Chile, vol. XXIII, núm. 2, diciembre de 2010, p. 30.

19 Así la opinión de Ambos, Kai, "Implementación del Estatuto de Roma...”, cit., p. 28. 
Esta revista forma parte del acervo de la Biblioteca Jurídica Virtual del Instituto de Investigaciones Jurídicas de la UNAM

del principio de legalidad en materia penal. Además, ya se ha observado que no hay una exigibilidad para que las legislaciones nacionales tipifiquen de forma exacta los crímenes competencia de la Corte, en tanto el artículo 20.3 del ER, que establece los principios de la "cosa juzgada", indica que "la Corte no procesará a nadie que haya sido procesado por otro tribunal en razón de hechos también prohibidos en virtud de los artículos 6, 7 u 8..." (es decir, los crímenes competencia de la Corte). Al aludir a "hechos" y no a "delitos" queda sobreentendido que no es exigible una tipificación idéntica. ${ }^{20}$

De otra parte, varios de los crímenes que prevé el ER se sancionan en la legislación nacional, ya por tratarse de figuras típicas que atentan contra bienes jurídicos básicos, homicidio o violación, por ejemplo, o bien porque han sido incorporados a la legislación penal en cumplimiento a compromisos internacionales (genocidio, esclavitud, prostitución forzada, tortura, desaparición forzada, algunos crímenes de guerra). En consecuencia, el sobreponer las figuras típicas del ER, sin analizar su impacto sobre las preexistentes en el CPF y la legislación especial, puede generar confusión y doble regulación.

Ahora bien, antes de proseguir con el desarrollo de esta cuestión, es preciso comentar que la inclusión de los tipos penales previstos en el ER en el CPF deja sin resolver el problema del fuero aplicable.

Recordemos que en México impera un sistema dual de competencias en materia penal y no por el hecho de que el genocidio, los crímenes de lesa humanidad y los crímenes de guerra se encuentren previstos en el CPF, todos los casos serán de la competencia automática de los tribunales federales, pues para que ello ocurra, es preciso que se surta alguna de las hipótesis previstas en el artículo 50, fracción I, de la Ley Orgánica del Poder Judicial de la Federación (LOPJF), que justamente señala cuáles son los delitos del orden federal.

De las trece hipótesis de competencia federal que contiene este artículo, sólo parece tener aplicabilidad aquella que convierte en federal el asunto cuando el sujeto activo del delito es un servidor público federal y, por tanto, todos los demás casos devendrían en una cuestión de los estados de la República, lo que no es algo menor, habida cuenta la disparidad existente en las legislaciones locales.

20 Véase Dondé Matute, Francisco Javier, op. cit., p. 118. 
Esta revista forma parte del acervo de la Biblioteca Jurídica Virtual del Instituto de Investigaciones Jurídicas de la UNAM

Por ello, hay un consenso en que, para asegurar la homogeniedad y coherencia de la legislación en esta materia, es importante que se considere de manera seria la opción de reservar a la Federación la implementación del Estatuto de Roma. ${ }^{21}$

Dondé Matute considera que esto se puede hacer a través de una ley especial, con base en las facultades implícitas que en materia de política exterior y celebración de tratados internacionales se otorgan al presidente de la República y la Cámara de Senadores. ${ }^{22}$ Dudo, sin embargo, que puede expedirse una ley penal con base en facultades implícitas, pues conllevaría una violación al principio de legalidad, vía la transgresión al principio derivado de "reserva de ley", el cual prevé que la facultad para fijar e imponer las penas por las faltas y delitos a nivel federal, corresponde en exclusiva al Congreso de la Unión, conforme al artículo 73, fracción XXI, de la Constitución general de la República, ${ }^{23}$ y si bien ese artículo y fracción establecen una facultad, constituyen a la vez una limitante, pues el Congreso de la Unión no podría expedir otras leyes penales que no sean las que expresamente le faculta la carta magna.

Así que tal vez, lo más conveniente sea adicionar el artículo 50, fracción I, de la LOPJF, al efecto de señalar que los casos que involucren genocidio, crímenes de lesa humanidad y crímenes de guerra serán de la competencia federal. Esta es una vía que ya se ha ensayado antes, como cuando en junio de 2000 se adicionaron los incisos 1 y $\mathrm{m}$ a la fracción I del citado artículo 50, con el propósito de considerar delitos federales los cometidos por o en contra de funcionarios electorales federales o de funcionarios partidistas en los términos de la fracción II del artículo 401 del CPF (hoy fracciones I y II) y los casos de tráfico de menores previstos en los artículos 366, fracción III (ya derogado); 366 ter y 366 quáter del mismo código, cuando el delito sea con el propósito de trasladar o entregar al menor fuera del territorio nacional.

Otra vía, probablemente más complicada en atención al proceso de reforma, es adicionar nuevamente la fracción XXI del artículo 73 de la Constitución federal, facultando al Congreso de la Unión para expedir una ley

21 Así, Guerrero, Humberto Francisco y Sirvent, María, op. cit., p. 40.

22 Véase Dondé Matute, Francisco Javier, op. cit., p. 132.

23 Sobre el principio de reserva de ley, véase la tesis bajo el rubro: "DELITOS CONTRA EL Ambiente y la Gestión ambiental. El artículo 420, FRACCión II, Del Código Penal Federal, NO ViOla el PRINCIPIO DE ReSERVA DE LeY”, Tesis 1a. CXCII/2011 (9a.), Semanario Judicial de la Federación y su Gaceta, Décima Época, t. 1, noviembre de 2012, p. 908. 
de aplicación federal en materia de los delitos de genocidio, lesa humanidad y de guerra. Nótese que se alude a una ley federal y no a una ley general, como las que ya existen o existirán en materia de secuestro, desaparición forzada de personas, otras formas de privación de la libertad contrarias a la ley, trata de personas, tortura y otros tratos o penas crueles, inhumanos o degradantes, así como electoral, pues de lo que se trata es de asegurar el cumplimiento de esta obligación internacional por parte de la Federación y no diluir su control entre todos los estados.

Así que, pensando en una incorporación al CPF de los delitos competencia de la Corte, realizaré el siguiente análisis respecto de los delitos de genocidio, lesa humanidad y de guerra.

\section{EL DELITO DE GENOCIDIO}

De conformidad con el artículo 6o. del ER, se entiende por genocidio cualquiera de los actos mencionados a continuación, perpetrados con la intención de destruir, total o parcialmente, a un grupo nacional, étnico, racial o religioso, como tal: a) matanza de miembros del grupo; b) lesión grave a la integridad física o mental de los miembros del grupo; c) sometimiento intencional del grupo a condiciones de existencia que hayan de acarrear su destrucción física, total o parcial; d) medidas destinadas a impedir los nacimientos en el seno del grupo, y e) traslado por fuerza de niños del grupo a otro grupo. ${ }^{24}$

En nuestro país, este delito se contempla en el artículo 149 Bis del CPF, adicionado por decreto publicado en el Diario Oficial de la Federación (DOF) el 20 de enero de 1967. Este ilícito sólo se contempla a nivel federal y es inexistente en las legislaciones penales de los estados de la República.

Dondé Matute ya ha resaltado que al hacer una comparación entre este tipo penal y los contemplados en la Convención Internacional contra el Genocidio de 1948 y el ER, se detectan dos diferencias sustanciales: a) el CPF limita el impedir nacimientos sólo por medio de la esterilización, cuando la definición internacional no hace tal distinción y $b$ ) el traslado de menores de un grupo a otro grupo, en el CPF va dirigido a menores de 16

24 Esta definición es idéntica a la contenida en la Convención para la Prevención y Sanción del Delito de Genocidio, adoptada en Nueva York el 9 de diciembre de 1948, de la que México es parte. 
Esta revista forma parte del acervo de la Biblioteca Jurídica Virtual del Instituto de Investigaciones Jurídicas de la UNAM

años, cuando las convenciones internacionales sólo hablan de "menores", lo que tiene una connotación más amplia. ${ }^{25}$ Concuerdo en la necesidad de que nuestra legislación adopte textualmente la definición de la Convención de 1948 y el ER.

Finalmente, es importante mencionar que la Convención citada, entre otras de sus hipótesis, contempla el compromiso de sancionar la instigación directa y pública a cometer genocidio, lo que claramente se establece en el artículo 25.3.e) del Estatuto y que si bien queda cubierta por el artículo 208, primera hipótesis, del CPF (provocar públicamente a cometer un delito), habría que ponderar su autonomía en razón de ese compromiso internacional y la cuantía de la pena, que ahora es mínima (diez a ciento ochenta jornadas de trabajo en favor de la comunidad), salvo que se consume el delito provocado.

\section{LOS CRÍMENES DE LESA HUMANIDAD}

Los "Crímenes de lesa humanidad" se contienen en el artículo 7o. del ER. Se trata de 11 conductas sujetas a los llamados "elementos contextuales"; ${ }^{26}$ es decir, condicionadas a que sean parte de un ataque generalizado o sistemático ${ }^{27}$ contra una población civil y con conocimiento de dicho ataque (este elemento contextual es y debe ser una parte del tipo penal).

25 Véase Dondé Matute, Francisco Javier, op. cit., p. 140.

26 Se les define como "elementos contextuales" en razón de que los delitos se cometen en un contexto determinado, que es, precisamente, el ataque generalizado o sistemático. Sobre esto véase: Pérez Caballero, Jesús, "Defensa de los elementos contextual y político de los crímenes de lesa humanidad contra la expansión del tipo al terrorismo internacional”, Revista Electrónica de Ciencia Penal y Criminología, España, núm. 15-15, 2013, p. 3, disponible en: http: / / criminet.ugr.es/recpc/15/recpc15-15.pdf (fecha de consulta: 15 de abril de 2016).

27 De acuerdo a la jurisprudencia de la CPI, por ataque generalizado se entiende aquel realizado a gran escala y con un número significativo de víctimas, mientras que sistemático será aquel que forma parte de un plan organizado, de forma tal que no constituya una repetición accidental de conductas criminales similares. Sobre esto, véase, Wolffhügel G., Christian, "El elemento contextual del crimen de lesa humanidad: una visión en el marco de las decisiones de la Corte Penal Internacional”, en Boeglin, Nicolás et al. (eds.), La Corte Penal Internacional: una perspectiva latinoamericana, San José, Costa Rica, Universidad para la Paz de las Naciones Unidas-University Press, 2012, p. 408. 
Esta revista forma parte del acervo de la Biblioteca Jurídica Virtual del Instituto de Investigaciones Jurídicas de la UNAM

Enseguida, me referiré a cada una de estas conductas y su correspondencia o no con el catálogo de delitos existente en la normativa nacional:

a) Asesinato. Sin ningún problema, esta conducta encuadra en el delito de homicidio previsto en el artículo 302 del CPF. Lo procedente aquí es hacer el reenvío correspondiente.

b) Exterminio. Esta conducta no aparece regulada en el ordenamiento penal. El artículo 7.2.b), del ER, señala que el "exterminio comprenderá la imposición intencional de condiciones de vida, entre otras, la privación del acceso a alimentos o medicinas, entre otras, encaminadas a causar la destrucción de parte de una población”. Esta definición tendría que adoptarse en la ley penal, eliminando las palabras "entre otras", a fin de no violar el principio de taxatividad.

c) Esclavitud. Acorde al artículo 7.2.c) del Estatuto, por "esclavitud" se entiende el ejercicio de los atributos del derecho de propiedad sobre una persona, o de algunos de ellos, incluido el ejercicio de esos atributos en el tráfico de personas, en particular mujeres y niños.

En el caso de nuestro país, este delito se define y sanciona en el artículo 11 de la Ley General para Prevenir, Sancionar y Erradicar los Delitos en Materia de Trata de Personas y para la Protección y Asistencia a las Víctimas de estos Delitos, según el cual la esclavitud consiste en "el dominio de una persona sobre otra, dejándola sin capacidad de disponer libremente de su propia persona ni de sus bienes y se ejerciten sobre ella, de hecho, atributos del derecho de propiedad”. $\mathrm{Al}$ existir este tipo penal en nuestra legislación, bastaría con hacer la remisión al artículo 11, segundo párrafo de la ley antes citada.

d) Deportación o traslado forzoso de población. No hay una definición legal para esta conducta. El artículo 7.2.d), del ER, indica que por "deportación o traslado forzoso de población se entenderá el desplazamiento forzoso de las personas afectadas, por expulsión u otros actos coactivos, de la zona en que estén legítimamente presentes, sin motivos autorizados por el derecho internacional". Aunque las palabras "deportación o traslado forzoso" se explican por sí mismas, no se observa inconveniente en que se adopte la definición contemplada en el ER.

e) Encarcelación u otra privación grave de la libertad física en violación de normas fundamentales de derecho internacional. No hay una definición exacta para esta conducta. El artículo 225, fracción XX, del CPF, sanciona al servidor público que ordene la aprehensión de un individuo por 
delito que no amerite pena privativa de libertad o en casos en que no preceda denuncia, acusación o querella o realice la aprehensión sin poner al detenido a disposición del juez en el término señalado por el párrafo tercero del artículo 16 de la Constitución; mientras que el artículo 364 del mismo código sanciona al particular que prive a otro de su libertad (privación ilegal de la libertad).

Atento a lo anterior, parecería preferible adoptar una definición propia en el código. Tal vez: "encarcelación u otra privación de la libertad (cualquiera que sea y no sólo "grave”), fuera de los casos permitidos por la ley o sin sujetarse a los procedimientos legales”.

f) Tortura. Respecto al delito de tortura, es pertinente señalar que México ha sido suscribiente, tanto de la Convención contra la Tortura y Otros Tratos o Penas Crueles, Inhumanos o Degradantes de las Naciones Unidas de 1984, como de la Convención Interamericana para Prevenir y Sancionar la Tortura de 1985 y que a la fecha este delito se encuentra tipificado en la legislación federal y en las legislaciones de los estados.

La Ley Federal para Prevenir y Sancionar la Tortura, publicada en el DOF el 27 de mayo de 1986, adoptó una definición cercana a la Convención Internacional de 1984, pero dejó fuera algunos aspectos contemplados en la Convención Interamericana de 1985 y a nivel estatal también pueden observarse esas disparidades.

Sin embargo, por decreto publicado en el DOF el 10 de julio de 2015, se adicionó la fracción XXI del artículo 73 constitucional, a efecto de otorgar al Congreso de la Unión la facultad de expedir las leyes generales en materia de desaparición forzada de personas y otras formas de privación de la libertad contrarias a la ley y de tortura y otros tratos o penas crueles, inhumanos o degradantes, por lo que actualmente se discute en la Cámara de Senadores la iniciativa de Ley General para Prevenir, Investigar y Sancionar los Delitos de Tortura y otros Tratos o Penas Crueles, Inhumanos o Degradantes, que presentó el presidente de la República el 10 de diciembre de 2015.

En razón de ello, tomaré como referencia el tipo penal de tortura que propone la ley general, cuya aprobación es previsible en el futuro cercano, para luego compararlo con el tipo penal del ER.

Conforme al artículo 21 de la iniciativa señalada: 
Comete el delito de tortura el servidor publico o el particular que con la autorización, el apoyo o la aquiescencia de un servidor público, mediante acto u omisión inflija dolosamente penas, dolores o sufrimientos físicos o psicológicos a una persona, con el fin de obtener de la persona torturada o de un tercero información o una confesión; coaccionarla para que realice o deje de realizar una conducta determinada; como medio intimidatorio o castigo personal por un acto que haya cometido o se sospeche haya cometido; como una medida preventiva o por razones basadas en discriminación o cualquier otro fin determinado.

De acuerdo a la fracción I del artículo 22 de la misma iniciativa, también comete el delito de tortura:

El servidor publico o el particular que con la autorización, el apoyo o la aquiescencia de un servidor público, dolosamente y con los fines establecidos en el artículo anterior aplique métodos tendientes a anular la personalidad o a disminuir la capacidad física o psicológica de la víctima, aunque no causen dolor físico o angustia psicológica.

Y, conforme a la fracción II:

El servidor público que siendo superior jerárquico de otros servidores públicos bajo su inmediata autoridad y control efectivos, haya tenido conocimienmto de que sus subordinados se proponían cometer o estuvieren cometiendo el delito tipificado en el artículo anterior y conscientemente haya sido omiso en tomar las acciones necesarias para prevenirlo o impedirlo.

Por su parte, el ER, en el artículo 7.2.e), señala que por:

Tortura se entenderá causar intencionalmente dolor o sufrimientos graves, ya sean físicos o mentales, a una persona que el acusado tenga bajo su custodia o control; sin embargo, no se entenderá por tortura el dolor o los sufrimientos que se deriven únicamente de sanciones lícitas o que sean consecuencia normal o fortuita de ellas.

Como vemos, asoman diferencias sustanciales, pues mientras en el proyecto legislativo no se exige que los dolores o sufrimientos sean graves, en la legislación internacional sí, pero en ésta los dolores o sufrimientos no tienen un fin o propósito específico (basta que se causen) y en la legislación 
Esta revista forma parte del acervo de la Biblioteca Jurídica Virtual del Instituto de Investigaciones Jurídicas de la UNAM

nacional sí tienen una finalidad determinada (obtener información o una confesión, etcétera).

Por otra parte, está la cuestión del sujeto activo, que en el derecho internacional penal posibilita que los crímenes puedan ser cometidos tanto por servidores públicos (parte de un Estado) como por ciudadanos (parte de una organización), derivado del artículo 7.2.a) del ER, que señala que por “ataque contra una población civil se entenderá una línea de conducta que implique la comisión múltiple de actos mencionados en el párrafo 1 contra una población civil, de conformidad con la política de un Estado o de una organización de cometer ese ataque o para promover esa política" (este ha sido denominado el "elemento político" de los delitos de lesa humanidad). ${ }^{28}$ De acuerdo con los "Elementos de los Crímenes", normativa derivada del artículo 9o. del ER, ${ }^{29}$ se entiende que la "política de cometer ese ataque" requiere que el Estado o la organización promueva o aliente activamente un ataque de esa índole contra una población civil.

En términos de la legislación nacional, los particulares sí podrían cometer tortura, pero sólo cuando obren con la autorización, el apoyo o la aquiescencia de un servidor público y no cuando actúen por sí mismos, lo que sabemos, sí es posible en términos del ER.

A fin de resolver estas discrepancias, se podría hacer una remisión al delito de tortura previsto en el artículo 21 del ahora proyecto de ley general sobre tortura, con el acotamiento de que las penas, dolores o sufrimientos físicos o psicológicos deben ser graves y no estarán sujetas a ninguna de las finalidades previstas en ese artículo (el adjetivo de "graves" sería el contrapeso a la ausencia de finalidad) y que, además, el sujeto activo del delito podrá ser cualquier persona, tal y como sucede en la legislación internacional.

g) Violación, esclavitud sexual, prostitución forzada, embarazo forzado, esterilización forzada o cualquier otra forma de violencia sexual de gravedad comparable. El delito de violación se prevé en el artículo 265 del CPF, por lo que bastaría hacer la remisión respectiva.

28 Sobre esta cuestión, véase Werle, Gerhard, Tratado de derecho penal internacional, trad. del alemán de Claudia Cárdenas Aravena, Jaime Cousi Salas y María Gutiérrez Rodríguez, 2a. ed., Valencia, Tirant Lo Blanch, 2011, p. 475.

29 El artículo 9.1 del ER señala que los elementos de los crímenes ayudarán a la Corte a interpretar y aplicar los artículos 6, 7 y 8 del Estatuto y serán aprobados por una mayoría de dos tercios de los miembros de la Asamblea de los Estados partes. 
Esta revista forma parte del acervo de la Biblioteca Jurídica Virtual del Instituto de Investigaciones Jurídicas de la UNAM

En cuanto a la "esterilización forzada" tiene aplicabilidad el artículo 199 Quintus del CPF, según el cual comete el delito de "esterilidad provocada" quien sin el consentimiento de una persona practique en ella procedimientos quirúrgicos, químicos o de cualquier otra índole para hacerla estéril. Aquí también cabría el reenvío correspondiente.

Respecto a la "prostitución forzada", el artículo 13 de la Ley General en Materia de Trata de Personas, sanciona al que se beneficie de la explotación de una o más personas a través de la prostitución, la pornografía, las exhibiciones públicas o privadas de orden sexual, el turismo sexual o cualquier otra actividad sexual remunerada mediante: I) el engaño; II) la violencia física o moral; III) el abuso de poder; IV) el aprovechamiento de una situación de vulnerabilidad; V) daño grave o amenaza de daño grave, o VI) la amenaza de denunciarle ante autoridades respecto a su situación migratoria en el país o cualquier otro abuso de la utilización de la ley o procedimientos legales, que provoque que el sujeto pasivo se someta a las exigencias del activo. Tratándose de personas menores de edad o personas que no tiene la capacidad de comprender el significado del hecho no se requerirá la comprobación de los medios arriba señalados.

Aquí también podría hacerse la remisión, únicamente respecto de la prostitución, con la aclaración de que no es necesario que el sujeto activo obtenga algún beneficio.

En cuanto a la conducta de "esclavitud sexual", la misma no aparece como sancionada en el orden jurídico mexicano. De acuerdo al artículo 7, 1), g)-2 de los "Elementos de los Crímenes", la esclavitud sexual requiere que el autor haya ejercido uno de los atributos del derecho de propiedad sobre una o más personas, como comprarlas, venderlas, prestarlas o darlas en trueque, o todos ellos, o les haya impuesto algún tipo similar de privación de libertad y que el autor haya hecho que esa o esas personas realizaran uno o más actos de naturaleza sexual.

Por su parte, el artículo 11, segundo párrafo de la Ley General en Materia de Trata de Personas, al que ya nos referimos antes, define a la esclavitud como "el dominio de una persona sobre otra, dejándola sin capacidad de disponer libremente de su propia persona ni de sus bienes y se ejerciten sobre ella, de hecho, atributos del derecho de propiedad".

En ese tenor, se puede señalar que por "esclavitud sexual” se entiende la conducta referida en el artículo 11, segundo párrafo, de la ley arriba citada, cuando la misma tenga por objeto la realización de actos de naturaleza sexual o la cópula. 
Siguiendo lo señalado en los artículos 260, tercer párrafo, y 265, segundo párrafo, del CPF, se deberá establecer que: a) por actos de naturaleza sexual se entienden los tocamientos o manoseos corporales obscenos o los que representen actos explícitamente sexuales u obliguen a la víctima a representarlos, y b) por cópula, la introducción del miembro viril en el cuerpo de la víctima por vía vaginal, anal u oral, independientemente de su sexo.

El crimen de "embarazo forzado" no existe en la legislación nacional. Únicamente se sanciona la inseminación artificial sin consentimiento de la mujer o aún con éste, si fuera menor o incapaz (artículo 466 de la Ley General de Salud), y el implantar a una mujer un óvulo fecundado, cuando hubiere utilizado para ello un óvulo ajeno o esperma de donante no autorizado, sin el consentimiento expreso de la paciente, del donante o con el consentimiento de una menor de edad o de una incapaz (artículo 199 quáter del CPF).

Sin embargo, no son éstos los sentidos a los que se refiere la normativa internacional, puesto que el artículo 7.2.f) del ER entiende por "embarazo forzado", el confinamiento ilícito de una mujer a la que se ha dejado embarazada por la fuerza, con la intención de modificar la composición étnica de una población o de cometer otras violaciones graves del derecho internacional.

Habría que hacer la tipificación correspondiente, pero dejando fuera el elemento subjetivo de "cometer otras violaciones graves del derecho internacional”, a fin de no afectar el principio de taxatividad.

En cuanto a la conducta de cometer "cualquier otra forma de violencia sexual de gravedad comparable”, debe quedar fuera con el propósito de no lesionar el principio de legalidad.

h) Persecución de un grupo o colectividad con identidad propia fundada en motivos políticos, raciales, nacionales, étnicos, culturales, religiosos, de género definido en el párrafo $3,^{30}$ u otros motivos universalmente reconocidos como inaceptables con arreglo al derecho internacional, en conexión con cualquier acto mencionado en el presente párrafo o con cualquier crimen de la competencia de la Corte. Esta conducta es complementada por el artículo 7.2.g) del

30 El artículo 7.3 del ER señala que "a los efectos del mismo se entenderá que el término "género» se refiere a los dos sexos, masculino y femenino, en el contexto de la sociedad. El término "género» no tendrá más acepción que la que antecede". 
Esta revista forma parte del acervo de la Biblioteca Jurídica Virtual del Instituto de Investigaciones Jurídicas de la UNAM

Estatuto, al señalar que por “persecución” se entenderá la privación intencional y grave de derechos fundamentales en contravención del derecho internacional en razón de la identidad del grupo o de la colectividad.

Se trata de un tipo de formulación compleja, pues la persecución debe realizarse en conexión con cualquiera de los actos constitutivos del crimen de lesa humanidad (asesinato, violación, esclavitud, etcétera) o con cualquier otro crimen competencia de la Corte, lo que no encuentra paralelo en la legislación nacional. No obstante ello, estimo que el delito puede ser tipificado de la manera más concreta posible y acorde al principio de legalidad, eliminando, por ejemplo, referencias genéricas, como "otros motivos universalmente reconocidos como inaceptables".

i) Desaparición forzada de personas. El artículo 7.2 i) del Estatuto señala que por "desaparición forzada de personas" se entenderá:

La aprehensión, la detención o el secuestro de personas por un Estado o una organización política, o con su autorización, apoyo o aquiescencia, seguido de la negativa a admitir tal privación de libertad o dar información sobre la suerte o el paradero de esas personas, con la intención de dejarlas fuera del amparo de la ley por un período prolongado.

Esta definición es similar a la establecida, tanto en la Convención Internacional para la Protección de Todas las Personas Contra las Desapariciones Forzadas de las Naciones Unidas, firmada en París el 6 de febrero de 2007, como en la Convención Interamericana sobre Desaparición Forzada de Personas, firmada en Belem do Para, Brasil, el 9 de junio de 1994, y de las cuales México es parte; las diferencias radican en que el tipo penal del Estatuto contempla la participación de particulares ("una organización política”), mientras que las convenciones internacionales la limitan a agentes del Estado o personas bajo su autorización o aquiescencia; asimismo, el ER señala que la desaparición debe tener por fin dejar a la persona fuera del amparo de la ley por "un periodo prolongado", cuando las convenciones internacionales no establecen tal limitante.

En el plano nacional, el delito de desaparición forzada de personas aparece regulado en el artículo 215-A del CPF y se contempla prácticamente 
en todas las legislaciones penales estatales, exceptuando Baja California Sur, Estado de México, Quintana Roo, Tabasco y Yucatán.

Ahora bien, como ya lo señalé antes, por decreto publicado en el DOF el 10 de julio de 2015, se adicionó la fracción XXI del artículo 73 constitucional, a efecto de otorgar al Congreso de la Unión la facultad de expedir la Ley General en Materia de Desaparición Forzada de Personas, por lo que actualmente se discute en la Cámara de Senadores la iniciativa de Ley General para Prevenir y Sancionar los Delitos en Materia de Desaparición de Personas, que presentó el presidente de la República el 10 de diciembre de 2015, por lo que en virtud de la inminencia de esta ley, tomaré como referencia los tipos penales que propone la iniciativa, para luego compararlos con el tipo penal del ER.

El proyecto distingue entre la desaparición forzada de personas y la desaparición por particulares. En cuanto al primero de los delitos, el artículo 20 indica que:

Comete el delito de desaparición forzada de personas, el o los servidores públicos o el particular o grupo de particulares que con la autorización, el apoyo o la aquiescencia de un servidor público, priven de la libertad a una o más personas, seguida de la negativa a reconocer dicha privación de la libertad, o a proporcionar la información disponible sobre la misma o su suerte o paradero, con lo cual, quien fue privado de la libertad, queda sustraído a la protección del ordenamiento jurídico.

Esto se complementa con lo dispuesto por el artículo 21, el cual indica que también comete el delito de desaparición forzada de personas:

I. El servidor público que siendo superior jerárquico de otros servidores públicos bajo su inmediata autoridad y control efectivos, haya tenido conocimiento de que sus subordinados se proponían cometer o estuvieren cometiendo el delito tipificado en el artículo anterior y, conscientemente, haya sido omiso en tomar las acciones necesarias para prevenirlo, impedirlo o hacerlo del conocimiento de las autoridades competentes [y] II. El servidor público o persona que por orden, con autorización, consentimiento, apoyo, aquiescencia o respaldo de un servidor público, a sabiendas de la comisión de cualquiera de las conductas señaladas en el presente Capítulo y sin haber participado directamente en las mismas, incinere, sepulte, desintegre o destruya total o parcialmente el cadáver o restos de la persona desaparecida. 
En cuanto al segundo de los tipos penales, la iniciativa indica, en su artículo 26, que comete el delito de desaparición por particulares:

La persona o grupo de personas que sin la autorización, el apoyo o la aquiescencia de un servidor público, priven de la libertad a una o mas personas con la finalidad de ocultarlas, seguida de la negativa a reconocer dicha privación de la libertad o a proporcionar la información disponible sobre su suerte o paradero, con lo cual, quien fue privado de la libertad, queda sustraído a la protección del ordenamiento jurídico.

Y, asimismo, conforme al artículo 27, se considerará:

Como partícipe del delito de desaparición por particulares, para los efectos de la ley, a la persona que a sabiendas de la comisión de cualquiera de las conductas señaladas en el presente Capítulo, incinere, sepulte, desintegre o destruya total o parcialmente el cadáver o restos de la persona desaparecida cuya muerte se haya producido durante la desaparición.

Se estima que la redacción propuesta para los delitos de desaparición de personas no se contrapone esencialmente con la contenida en el Estatuto e incluso el tipo penal de desaparición por particulares permite la sanción de los crímenes cometidos por "una organización política". Se evidencia, sin embargo, que el tipo penal del ER alude a la intención del sujeto activo del delito de dejar a la persona fuera del amparo de la ley "por un periodo prolongado", lo que, como ya se ha observado antes, reduce el ámbito de aplicación de la norma, ${ }^{31}$ pero no se observa problema alguno para la remisión a los artículos correspondientes, ya que los tipos penales de nuestro país, en ese sentido, otorgan un mayor ámbito de protección.

j) El crimen de apartheid. El artículo 7.2.h) del Estatuto señala que por "el crimen de apartheid" se entenderán los “actos inhumanos de carácter similar a los mencionados en el párrafo 1 cometidos en el contexto de un régimen institucionalizado de opresión y dominación sistemáticas de un grupo racial sobre uno o más grupos raciales y con la intención de mantener ese régimen”.

31 Cfr. Dondé Matute, Francisco Javier, op. cit., p.139. 
Esto supondría que, de manera similar al crimen de persecución, la conducta base está conectada a la comisión de un crimen competencia de la Corte, específicamente, en este caso, cualquiera de los actos señalados en el parrafo $1 \mathrm{del}$ artículo 7o., como pueden ser asesinato, tortura, violación, esclavitud, etcétera.

Ahora bien, por otra parte tenemos la Convención Internacional sobre la Represión y el Castigo del Crimen de Apartheid, firmada en Nueva York el 30 de noviembre de 1973 de la que México es parte, en donde se señala que la expresión "crimen de apartheid" incluirá las políticas y prácticas análogas de segregación y discriminación racial tal como se practican en el África meridional y denotará los siguientes actos inhumanos cometidos con el fin de instituir y mantener la dominación de un grupo racial de personas sobre cualquier otro grupo racial de personas y de oprimirlo sistemáticamente, a saber:

a) La denegación a uno o más miembros de uno o más grupos raciales del derecho a la vida y a la libertad de la persona: i) mediante el asesinato de miembros de uno más grupos raciales; ii) mediante atentados graves contra la integridad física o mental, la libertad o la dignidad de los miembros de uno o más grupos raciales, o su sometimiento a torturas o a penas o tratos crueles, inhumanos o degradantes; iii) mediante la detención arbitraria y la prisión ilegal de los miembros de uno o más grupos raciales.

b) La imposición deliberada a uno o más grupos raciales de condiciones de existencia que hayan de acarrear su destrucción física, total o parcial.

c) Cualesquiera medidas legislativas o de otro orden destinadas a impedir a uno o más grupos raciales la participación en la vida política, social, económica y cultural del país y a crear deliberadamente condiciones que impidan el pleno desarrollo de tal o tales grupos, en especial denegando a los miembros de uno o más grupos raciales los derechos humanos y libertades fundamentales, entre ellos, el derecho al trabajo, el derecho a formar asociaciones sindicales reconocidas, el derecho a la educación, el derecho a salir de su país y a regresar al mismo, el derecho a una nacionalidad, el derecho a la libertad de circulación y de residencia, el derecho a la libertad de opinión y de expresión y el derecho a la libertad de reunión y de asociación pacíficas. 
d) Cualesquiera medidas, incluidas las de carácter legislativo, destinadas a dividir la población según criterios raciales, creando reservas y ghettos separados para los miembros de uno o más grupos raciales, prohibiendo los matrimonios mixtos entre miembros de distintos grupos raciales y expropiando los bienes raíces pertenecientes a uno o más grupos raciales miembros de los mismos.

e) La explotación del trabajo de los miembros de uno o más grupos raciales, en especial sometiéndolos a trabajo forzoso.

f) La persecución de las organizaciones y personas que se oponen al apartheid privándolas de derechos y libertades fundamentales.

Como puede verse, el crimen de apartheid se da en un contexto determinado, como lo es un régimen institucionalizado de opresión y dominación sistemáticas de un grupo racial sobre uno o más grupos raciales, en conexión con un crimen o conducta específica, por lo que se puede adoptar sin problema la definición contenida en el ER, que frente a la definición de la Convención, es más económica en palabras. De paso, se aprovecha para que México cumpla con el compromiso internacional de sancionar el crimen de apartheid, lo cual no ha hecho hasta el momento.

g) Otros actos inhumanos de carácter similar que causen intencionalmente grandes sufrimientos o atenten gravemente contra la integridad física o la salud mental o física. Esta hipótesis, que permite la aplicación análogica de la ley penal, debe quedar fuera a la luz de la prohición expresa del tercer párrafo del artículo 14 constitucional.

Finalmente, es oportuno reflexionar sobre la pena que sería aplicable a los delitos de lesa humanidad, que suponen una de las graves afrentas al género humano. El ER sanciona los crímenes competencia de la Corte con penas que pueden ir de 1 a 30 años de reclusión o bien reclusión a perpetuidad, cuando lo justifiquen la extrema gravedad del crimen y las circunstancias personales del condenado (artículo 77). Pero, en contrapartida, se contempla la posibilidad de un examen de reducción de la pena, cuando el recluso haya cumplido las dos terceras partes de la pena o 25 años de prisión en caso de reclusión perpetua (artículo 110).

En el caso de nuestro país, algunos delitos, individualmente considerados, pueden alcanzar penas exhorbitantes y aun sin posibilidad de reduc- 
ción; por ejemplo, el delito de secuestro tiene una pena estándar de 40 a 80 años de prisión, pero con agravantes puede llegar a los 110 y si se priva de la vida al secuestrado, hasta los 140, mientras que para el delito de desaparición de personas, se proponen penas de hasta 100 años de prisión. ¿Habríamos de sancionar nosotros los crímenes de lesa humanidad con penas aún más elevadas o sería necesario entrar en un caminio de racionalidad?

Desde mi punto de vista, nuestro país necesita una reflexión muy seria sobre esta cuestión, como lo hizo ver el reciente pronunciamiento de la Comisión Nacional de los Derechos Humanos sobre la Racionalización de la Pena de Prisión ${ }^{32}$ pero, desafortunadamente, no es éste el espacio para tratar tan delicado tema. No obstante, puede considerarse que los crímenes de lesa humanidad pudieran tener una pena estandarizada de 20 a 40 años de prisión con independencia de la pena aplicable al delito cometido. No es lo deseable, pero es lo posible.

\section{LOS CRÍMENES DE GUERRA}

Los crímenes de guerra se contemplan en al artículo 8o. del Estatuto. Se trata de un catálogo extenso de conductas que sancionan tanto las infracciones graves de los Convenios de Ginebra del 12 de agosto de 1949, como otras violaciones graves de las leyes y usos aplicables en los conflictos armados internacionales y no internacionales.

En otras palabras, estas normas sancionan las transgresiones al derecho internacional humanitario (DIH), entendido como el conjunto de normas que: a) tienden a dar protección a las víctimas de los conflictos armados (internacionales o no internacionales) y $b$ ) que restringen el uso de la fuerza por parte de los Estados a partir de la regulación de los métodos y medios de hacer la guerra. ${ }^{33}$

32 Véase el documento: Comisión Nacional de los Derechos Humanos, Racionalización de la pena de prisión. Pronunciamiento, México, 2016, disponible en: http: / / www.cndh.org.mx/sites / all/doc/Informes/Especiales/Pronunciamiento_20160331.pdf (fecha de consulta: 20 de junio de 2016).

33 Véase Vinuesa, Raúl Emilio, Derechos humanos y derecho internacional humanitario. Diferencias y complementariedad, Ginebra, Comité Internacional de la Cruz Roja, 1998, p. 2, disponible en: https://www.icrc.org/spa/resources/documents/misc/5tdlj8.htm (fecha de consulta: 5 de 
Esta revista forma parte del acervo de la Biblioteca Jurídica Virtual del Instituto de Investigaciones Jurídicas de la UNAM

El referido artículo 8o. del Estatuto tiene tres apartados. El primero (8.1) establece la competencia de la Corte respecto de los crímenes de guerra, en particular cuando se cometan como parte de un plan o política o como parte de la comisión en gran escala de tales crímenes.

El segundo (8.2) señala qué se entiende por “crímenes de guerra”, a saber: a) infracciones graves de los Convenios de Ginebra del 12 de agosto de 1949, para lo cual se enlistan ocho conductas cometidas contra personas o bienes protegidos por las disposiciones del Convenio de Ginebra pertinente; $b$ ) otras violaciones graves de las leyes y usos aplicables en los conflictos armados internacionales dentro del marco establecido de derecho internacional, enlistando las 26 conductas aplicables; c) en caso de conflicto armado que no sea de índole internacional, las violaciones graves del artículo 3o. común a los cuatro Convenios de Ginebra del 12 de agosto de 1949, enlistando cuatro actos cometidos contra personas que no participen directamente en las hostilidades, incluidos los miembros de las fuerzas armadas que hayan depuesto las armas y las personas puestas fuera de combate por enfermedad, herida, detención o por cualquier otra causa, y d) otras violaciones graves de las leyes y los usos aplicables en los conflictos armados que no sean de índole internacional, dentro del marco establecido de derecho internacional, enumerando 15 actos punibles.

Finalmente, el tercer apartado (8.3), indica que nada de lo dispuesto en el párrafo 2, incisos c y e del artículo 8o. afectará a la responsabilidad que incumbe a todo gobierno de mantener o restablecer el orden público en el Estado o de defender la unidad e integridad territorial del Estado por cualquier medio legítimo.

Ahora bien, las disposiciones de los Convenios de Ginebra se captan parcialmente en la legislación nacional a través de los delitos de: a) "violación de los deberes de humanidad” de heridos y prisioneros de guerra, y b) de homicidio y lesiones de prisioneros de guerra o fuera de los combates, este último dentro del rubro del delito de Rebelión (artículos 136, 137 y 149 del CPF y sus similares en las legislaciones estatales).

marzo de 2016; también Swinarski, Christophe, "Derecho internacional humanitario como sistema de protección de la persona humana en su relación con el Derecho internacional de los derechos humanos", en Fraidenraij, Susana y Méndez Silva, Ricardo (comps.), Elementos de derecho internacional humanitario, México, UNAM, Instituto de Investigaciones Jurídicas, 2001, p. 40. 
Esta revista forma parte del acervo de la Biblioteca Jurídica Virtual del Instituto de Investigaciones Jurídicas de la UNAM

Asimismo, el Código de Justicia Militar acusa la misma fragmentaria recepción de los Convenios de Ginebra y otras violaciones graves a las leyes o costumbres de guerra, a través de los "delitos contra el derecho de gentes" (artículos 209 y 215) y algunas de las hipótesis de los delitos de "maltrato a prisioneros, detenidos o presos y heridos" y de "pillaje, devastación, merodeo, apropiación de botín, contrabando, saqueo y violencias contra las personas" (artículos 324 y 325).

En resumen, las regulaciones respecto a los crímenes de guerra contemplados en los Convenios de Ginebra de 1949 y en sus Protocolos Adicionales I y II de 1977, se captan parcial y deficientemente por el orden jurídico mexicano, siendo necesaria una reingeniería de los tipos penales correspondientes. De otra parte, resalta que prácticamente la tercera parte de las legislaciones penales de los estados no contienen previsiones al respecto.

Concerniente al denominado "derecho de La Haya", que como sabemos restringe los métodos y los medios de combate, ${ }^{34}$ existen alrededor de 20 instrumentos internacionales que acusan igual recepción fragmentaria o incompleta.

En conclusión, y como ya se ha señalado antes, la regulación en nuestro país respecto a los crímenes de guerra es incipiente ${ }^{35}$ y parcial, lo que nos imposibilita para hacer un examen comparado con los tipos del ER.

Sin embargo, como con todo acierto se ha indicado, debido a la relación del Estatuto con otros tratados internacionales, su implementación también representa "una oportunidad para armonizar la legislación nacional con otras obligaciones internacionales reconocidas y aceptadas por el Estado Mexicano". ${ }^{36}$

México ha suscrito los cuatro Convenios de Ginebra de 1949 y el Protocolo adicional I de 1977 relativo a la protección de las víctimas de los

$34 \mathrm{Al}$ respecto, es importante recordar que el derecho internacional humanitario ha fusionado el denominado "derecho de Ginebra" - es decir, el conjunto de normas sobre la protección debida a las personas que se encuentran en poder del adversario - y el llamado "derecho de La Haya", que se constituye por el conjunto de normas relativas a la conducción de las hostilidades. Sobre ello, véase Bugnion, François, "El Derecho de Ginebra y el Derecho de La Haya”, Revista Internacional de la Cruz Roja, Suiza, núm. 844, 31 de diciembre de 2001, pp. 901 y ss., disponible en: https: / / www.icrc.org/spa/resources/documents/misc/5tdqeh.htm (fecha de consulta: 11 de marzo de 2016).

35 Véase Guerrero, Humberto Francisco y Sirvent, María, op. cit., p. 114.

36 Ibidem, p. 30. 
Esta revista forma parte del acervo de la Biblioteca Jurídica Virtual del Instituto de Investigaciones Jurídicas de la UNAM

conflictos armados internacionales, así como al menos 20 convenciones y protocolos en materia de regulación de los métodos y medios de hacer la guerra, de todos los cuales derivan compromisos internacionales que no se han cumplido o se han cumplido parcialmente, ${ }^{37}$ por lo que la regulación y definición de los crímenes de guerra en el CPF sería una excelente oportunidad para saldar estos compromisos.

Ahora bien, respecto a cómo incorporar estos crímenes a nuestra legislación, probablemente la mejor solución no sea la transcripción literal del artículo 8o. del ER. En primer lugar, porque la división entre crímenes de guerra de carácter internacional y los de carácter no internacional es innecesaria y, además, resulta anticuada, tomando en consideración la amplia asimilación del derecho aplicable a ambos tipos de conflictos ${ }^{38} \mathrm{y}$, en segundo lugar, porque el artículo 8o. deja de contemplar algunos crímenes de guerra. Al respecto, en una comparación realizada por la Cruz Roja Internacional, ${ }^{39}$ se detectó que las siguientes infracciones graves al Protocolo adicional I de los Convenios de Ginebra, no están incluidas en el ER:

a) Lanzar un ataque contra obras o instalaciones que contengan fuerzas peligrosas a sabiendas de que ese ataque causará muertos o heridos entre la población civil o daños a bienes de carácter civil, que sean excesivos.

b) Demorar injustificablemente la repatriación de prisioneros de guerra o de personas civiles.

c) Las prácticas del apartheid y demás prácticas inhumanas y degradantes, basadas en la discriminación racial que entrañen un ultraje contra la dignidad personal, cuando se cometan intencionalmente y en violación de los Convenios de Ginebra o del Protocolo I.

Por otra parte, es importante referir que no existe una definición de las armas, proyectiles, materiales y métodos de guerra que, por su propia natu-

37 Mayores datos sobre esta cuestión pueden encontarse en mi libro Introducción al derecho penal de los tratados internacionales en México, México, Porrúa, 2011.

38 Sobre esto, véase Werle, Gerhard, op. cit., p. 569.

39 Véase Comité Internacional de la Cruz Roja, Los crímenes de guerra según el Estatuto de Roma de la Corte Penal Internacional y su base en el derecho internacional humanitario. Cuadro comparativo, Ginebra, Suiza, 2008, pp. 20 y 21, disponible en: www.icrc.org/spa/assets/files/other/ sp_crimenes_de_guerra_cuadro_comparativo.pdf (fecha de consulta: 26 de junio de 2016). 
raleza, causen daños superfluos o sufrimientos innecesarios o surtan efectos indiscriminados en violación del derecho internacional de los conflictos armados, previstos en el artículo 8.2.b).xx) del Estatuto, pues no han sido objeto de una prohibición completa ni están incluidos en un anexo en virtud de una enmienda aprobada por los Estados parte, según se prevé en el mismo artículo.

Por ello, y siguiendo la recomendación de la Comisión Andina de Juristas, se propone la creación de un capítulo único sobre estos crímenes, siguiendo una clasificación de orden material como la siguiente: (I) protección de personas protegidas por el DIH, (II) protección de bienes protegidos por el DIH, (III) protección de misiones humanitarias, (IV) proscripción de ciertos medios para la conducción de las hostilidades, y (V) proscripción del uso, producción y distribución de ciertas armas en los combates. ${ }^{40}$

Por otra parte, y en relación con este tema, me gustaría referirme al fuero aplicable a los militares que cometan crímenes de guerra en el contexto de un conflicto armando. La cuestión no es muy complicada, pues a raíz de la reforma de junio de 2014 al artículo 57 del Código de Justicia Militar, motivada a su vez por la sentencia dictada por la Corte Interamericana de Derechos Humanos en el caso de Rosendo Radilla, cuando los afectados sean personas civiles (por ejemplo, un movimiento interno armado), el fuero aplicable es el del orden común, pero sería aplicable el fuero militar en caso de conflicto con un ejército enemigo.

Por último, y respecto de los crímenes de guerra, sí habría oportunidad de meditar sobre la cuantía de la pena en un marco de racionalidad y de acuerdo a los fines del derecho penal.

\section{CONCLUSIONES}

Con esto terminamos el análisis comparado entre el ER y la legislación penal nacional en materia de los delitos de genocidio, lesa humanidad y de guerra. Observamos, a través de este proceso, que es posible incorporar las disposiciones del Estatuto sin mayores dificultades técnicas, por lo que concluimos que lo que hace falta es la voluntad política de hacerlo.

40 Comisión Andina de Juristas, Lineamientos para la implementación del Estatuto de Roma, Lima, Perú, Comisión Andina de Juristas, 2008, pp. 14 y 15. 
Algunas cuestiones importantes a considerar en esta implementación son, en primer término, la incorporación al CPF de los tipos penales del derecho internacional penal y el aprovechamiento de las figuras preexistentes en la legislación nacional a fin de evitar antinomias y, en segundo, asegurar la aplicación federal en los procedimientos que resulten, lo que garantiza un manejo uniforme y puntual.

Probablemente éste no sea un punto urgente de la agenda nacional, pero sí representa un compromiso internacional que México debe cumplir, no sólo a la luz del Estatuto, sino de otros convenios internacionales. Además, es una oportunidad para demostrar el interés de nuestro país en la persecución de los crímenes más graves contra la humanidad y la defensa de los derechos humanos.

Hago votos porque esta cuestión pueda ser abordada a la brevedad y se de él paso decisivo en esta materia.

\section{FUENTES DE INFORMACIÓN}

Ambos, Kai, "Implementación del Estatuto de Roma en la legislación nacional”, en Ambos, Kai y Malarino, Ezequiel (eds.), Persecución penal nacional de crímenes internacionales en América Latina y España, Uruguay, Fundación Konrad-Adenauer-Stiftung, 2003.

, "La implementación del Estatuto de la Corte Penal Internacional en Alemania", Revista Electrónica de Ciencia Penal y Criminología, España, núm. 7, 2005, disponible en: http: / / criminet.ugr.es/recpc/07/recpc07-17. pdf ( fecha de consulta: 20 de abril de 2016).

Bugnion, François, "El derecho de Ginebra y el derecho de La Haya", Revista Internacional de la Cruz Roja, núm. 844, 31 de diciembre de 2001, disponible en: https://www.icrc.org/spa/resources/documents/misc/5tdqeh. htm (fecha de consulta: 11 de marzo de 2016).

CÁrdenas Aravena, Claudia, "La implementación de los crímenes competencia de la Corte Penal Internacional en la Ley No. 20.357”, Revista de Derecho, Chile, vol. XXIII, núm. 2, diciembre de 2010.

Chirino SÁnCHEZ, Alfredo, "La reforma penal y los delitos competencia de la Corte Penal Internacional”, en BoEglin, Nicolás et al. (eds.), La Corte 
Esta revista forma parte del acervo de la Biblioteca Jurídica Virtual del Instituto de Investigaciones Jurídicas de la UNAM

Penal Internacional: una perspectiva latinoamericana, Costa Rica, Universidad para la Paz de las Naciones Unidas-University Press, 2012.

COMISIÓN ANDINA DE JURISTAS, Lineamientos para la Implementación del Estatuto de Roma. Lima, Perú, Comisión Andina de Juristas, 2008.

Comisión Nacional de los Derechos Humanos, Racionalización de la pena de prisión. Pronunciamiento, México, 2016, disponible en: http: / / www. cndh.org. $\mathrm{mx} /$ sites / all / doc/Informes / Especial / Pronunciamiento_20160331. pdf (fecha de consulta: 20 de junio de 2016).

COMité InTERnACIONAL DE LA CRUZ ROJA, Los crímenes de guerra según el Estatuto de Roma de la Corte Penal Internacional y su base en el derecho internacional humanitario. Cuadro comparativo, Suiza, 2008, disponible en: www. icrc.org/spa/assets/files/other/sp_crimenes_de_guerra_cuadro_comparativo.pdf (fecha de consulta: 26 de junio de 2016).

DONDÉ MATUTE, Francisco Javier, "Consideraciones en torno a la implementación de los crímenes que son competencia de la Corte Penal Internacional", Anuario Mexicano de Derecho Internacional, México, vol. VII, 2007.

Guerrero Rosales, Humberto Francisco y Sirvent Bravo Ahuja, María (coords.), Manual para la Implementación del Estatuto de Roma en la Legislación Mexicana, México, Comisión Mexicana de Defensa y Promoción de los Derechos Humanos, 2008.

Herencia Carrasco, Salvador Martín, La implementación del Estatuto de Roma en la Región Andina. Los casos de Bolivia, Colombia y Perú, Perú, Comisión Andina de Juristas, 2015.

PÉrez CABallero, Jesús, "Defensa de los elementos contextual y político de los crímenes de lesa humanidad contra la expansión del tipo al terrorismo internacional", Revista Electrónica de Ciencia Penal y Criminología, España, núm. 15-15, 2013, disponible en: http: / / criminet.ugr.es/recpc/15/ recpc15-15.pdf (fecha de consulta 15 de abril de 2016).

RoXin, Claus, Derecho penal. Parte general. Fundamentos. La estructura de la teoría del delito, trad. y notas por Diego Manuel Luzón Peña, Miguel Díaz y García Conlledo y Javier de Vicente Remesal, Madrid, Civitas, 2000.

SWINARSKI, Christophe, "Derecho internacional humanitario como sistema de protección de la persona humana en su relación con el Derecho internacional de los derechos humanos", en FRAIDENRAIJ, Susana y MÉNDEZ SILVA, Ricardo (comps.), Elementos de derecho internacional humanitario, México, UNAM,Instituto de Investigaciones jurídicas 2001. 
Villarreal Palos, Arturo, Introducción al derecho penal de los tratados internacionales en México, México, Porrúa, 2011.

VINUESA, Raúl Emilio, Derechos humanos y derecho internacional humanitario. Diferencias y complementariedad, Suiza, Comité Internacional de la Cruz Roja, 1998, disponible en: https: / /www.icrc.org/spa/resources/documents/ misc/5tdlj8.htm (fecha de consulta: 5 de marzo de 2016).

WERLE, Gerhard, Tratado de derecho penal internacional, trad. del alemán por Claudia Cárdenas Aravena, Jaime Cousi Salas y María Gutiérrez Rodríguez, 2a. ed., Valencia, Tirant Lo Blanch, 2011.

WolfFHüGel G., Christian, "El elemento contextual del crimen de lesa humanidad: una visión en el marco de las decisiones de la Corte Penal Internacional”, en BoEGLin, Nicolás et al. (eds.), La Corte Penal Internacional: una perspectiva latinoamericana, San José, Costa Rica, Universidad para la Paz de las Naciones Unidas-University Press, 2012. 